\title{
Optimization Analysis on Upper Filter System of Mechanical Water Treatment Equipment Based on Strength
}

\author{
Ying Gao ${ }^{1}$, De-zhen Feng ${ }^{2}$ and Jian-hau Sun ${ }^{2}$ \\ ${ }^{1}$ School of Management, University of Jinan, Jinan 250022, China \\ ${ }^{2}$ School of Mechanical Engineering, University of Jinan, Jinan 250022, China
}

\begin{abstract}
Domestic water treatment is very important field. Now, mechanical water treatment technology is getting wide use in production. In the process of life water treatment, filter process is a very important step. In this paper, the strength and deformation of upper filter system which includes upper filter frames and upper filter plates were analyzed with ANSYS and useful results are got. Through the analysis on strength, the paper found the shortcomings of production and design. After analyzing and comparing the stresses and deformations of three different design schemes, the paper provided the optimized design plan of upper filter system at last.
\end{abstract}

\section{Introduction}

As everyone knows, the average water resource of every person is very low, especially in northern China. Further more, the most water of our country is surface water and the components of the water are very complicated. This will threaten the safety of the water for life especially for rural water for life. So it is a very important to protect and apply the surface water scientifically. On the other hand, most parts of our country are mountains and desert. The available land resource is not abundant. With the increase of the population, the development of the economy and the quickening of urbanization process, the land resources will get more and more precious. So how to save in water treatment project has become an important subject.

Now the conventional water plants of our country use steel concrete structures as the main constructions which need large land and large building project which will cost long time and much money. On the other hand, the conventional water plants are not flexible in work. So the modular mechanical water treatment plants are getting wider and wider use because they need low invest, short time limit, small land and have the advantages of flexibility, high automation and easy operation. The water treatment plant consists of several independent treatments which are composed of three parts: flocculation system, sedimentation system and filter system, as are shown in Fig. 1 and Fig. 2.

According to the characteristics of modular mechanical water treatment equipment, this paper has analyzed the strength and stiffness of the upper filter system, discussed the stress and the deformation of the filter frame and plate. At last, combining theory with practice, the paper has improved and optimized the design of filter system.

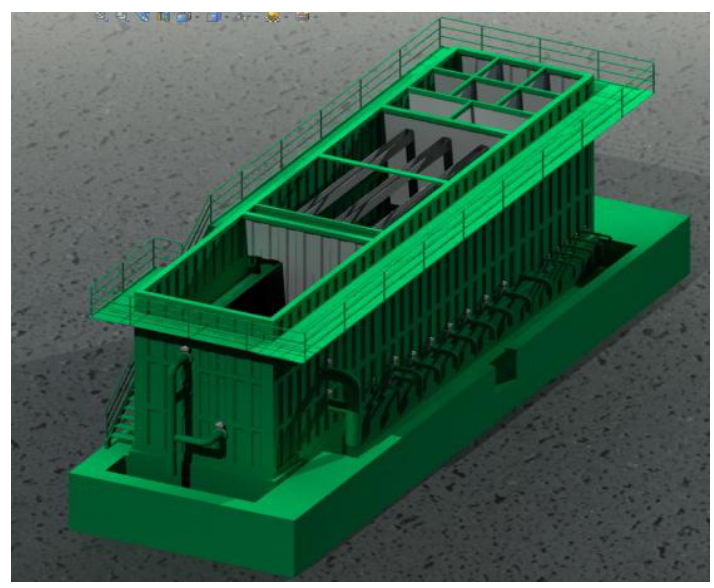

Figure 1. Mechanical water treating equipment

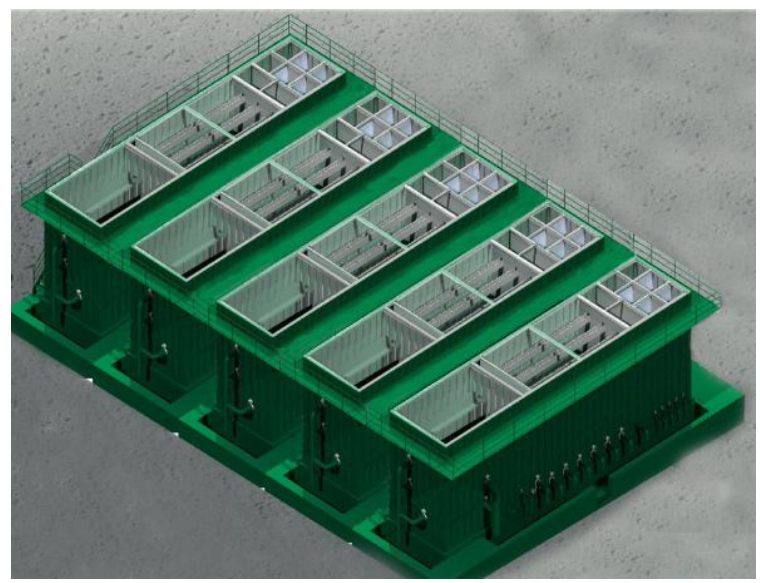

Figure 2. Mechanical water treating plant 
According to the characteristics of modular mechanical water treatment equipment, this paper has analyzed the strength and stiffness of the upper filter system, discussed the stress and the deformation of the filter frame and plate. At last, combining theory with practice, the paper has improved and optimized the design of filter system.

\section{Structure of filter systems}

According to the requirement of practical production, the filter systems should be changed in time to adapt to the need of production process. The filter systems are composed of upper and lower filter systems. In the upper filter system, filter plate uses $30 \mathrm{~mm}$ PVC plate on which a number of filters are mounted, the filter frame uses $3 * 9$ layout plan, i.e. three $120 * 80 * 5 \mathrm{~mm}$ longitudinal steel tubes and nine $120 * 80 * 5 \mathrm{~mm}$ transverse steel tubes which all are welded to the longitudinal tubes. Under the middle longitudinal beam, there are four uniformly distributed $80 * 80 * 5 \mathrm{~mm}$ upright columns, as shown in Fig. 1. The lower filter frame uses $3 * 9$ layout plan, i.e. three $80 * 80 * 5 \mathrm{~mm}$ longitudinal beam and nine $80 * 80 * 5 \mathrm{~mm}$ transverse beams. The supports columns are twelve $(3 * 4)$ uniformly distributed $80 * 80 * 5 \mathrm{~mm}$ upright steel tubes. The paper only studies the upper filter system.

In practice, the water treatment plant uses one layer or two layers homogeneous filter materials in one filter chamber which includes frames, filter plates, filter materials etc. Filter frames support the filter plates and filter plates bear the gravity of filter materials. The upper layer filter materials are quartz sands whose density is about $2.6 \mathrm{~g} / \mathrm{cm} 3$ and stacking density is $1.6 \mathrm{~g} / \mathrm{cm} 3$. The filter plates are rigid plastic PVC plates whose thickness is $30 \mathrm{~mm}$. The filter frames are composed of Q235B steel tubes whose size is $120 * 80 * 5 \mathrm{~mm}$ and the supporting tubes' size is $80 * 80 * 5 \mathrm{~mm}$.

\section{Strength analysis of original upper filter system}

In the upper filter system, the filter plate uses $30 \mathrm{~mm}$ PVC plate in which a number of filters are mounted. The filter frame uses $3 * 9$ layout plan, i.e. three $120 * 80 * 5 \mathrm{~mm}$ longitudinal tubes and nine $120 * 80 * 5 \mathrm{~mm}$ transverse steel tubes. There are four uniformly distributed $80 * 80 * 5 \mathrm{~mm}$ upright square tubes that support the longitudinal beam, as shown in Fig. 1. In transverse direction, the frame uses nine $120 \times 80 \times 5 \mathrm{~mm}$ rectangular steel tubes which all are welded to the longitudinal beam. The load of quartz sand is about $0.02785 \mathrm{MPa}$.

For the rectangular sheets with usual constraints, we can use theoretical formulae to compute $[1,2]$. But for the complicated combination of beams and sheets, the theoretical formulae can not be used to analyze the strength. In this case, numerical calculation must be used. In this paper, the FEM software ANSYS is used to calculate the stress and deformation of complicated structures [3-6]. Fig. 3 is the FEM model of the upper filter system, Fig. $4 \sim 6$ are the analytical results of upper filter system under normal work load. Where, Fig. 4 is the stress picture of upper filter system, Fig. 5 and Fig. 6 is for stress pictures of the filter plate frame and filter plate respectively. In the analysis, the modulus of elasticity of the filter plate is $3000 \mathrm{MPa}$.

When the periodic back washes are needed, the load will increase to $0.05 \mathrm{MPa}$. Fig. $7 \sim 8$ are the analytical results of upper filter system under back wash load.

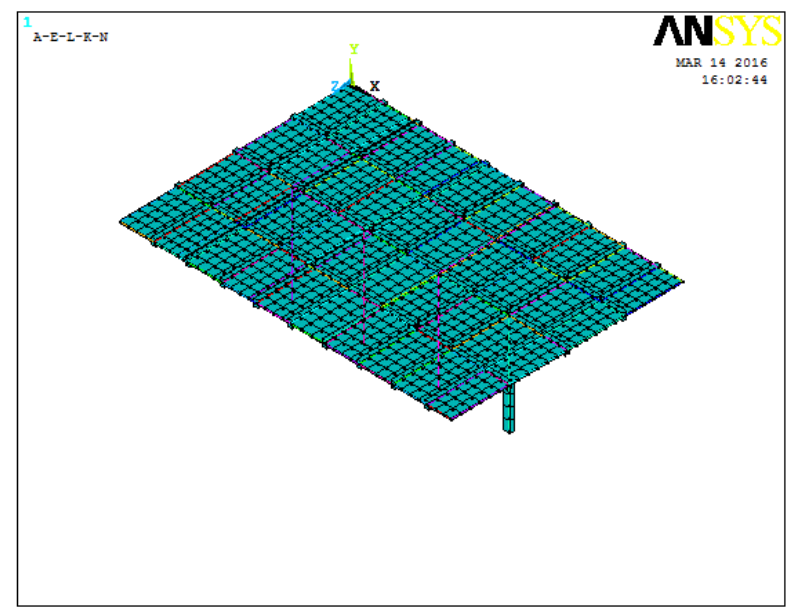

Figure 3. Model of upper filter system

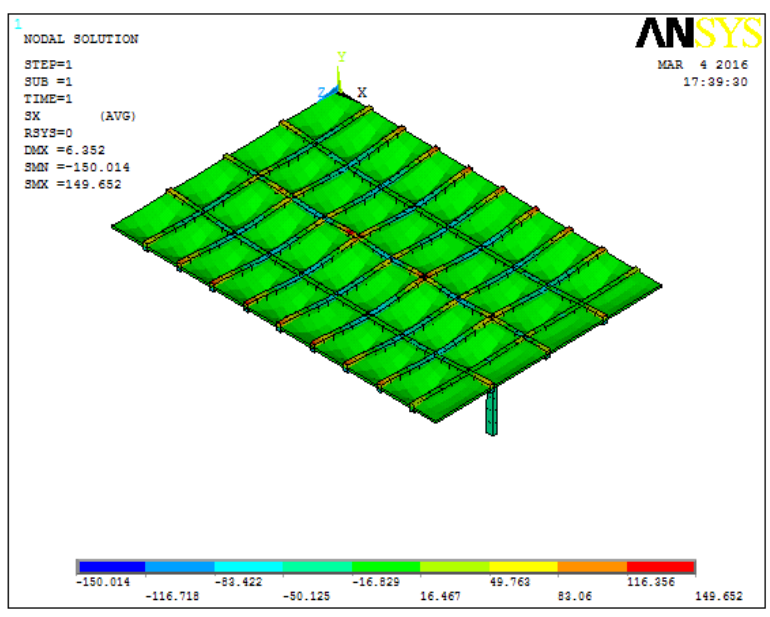

Figure 4. Stress of upper filter system

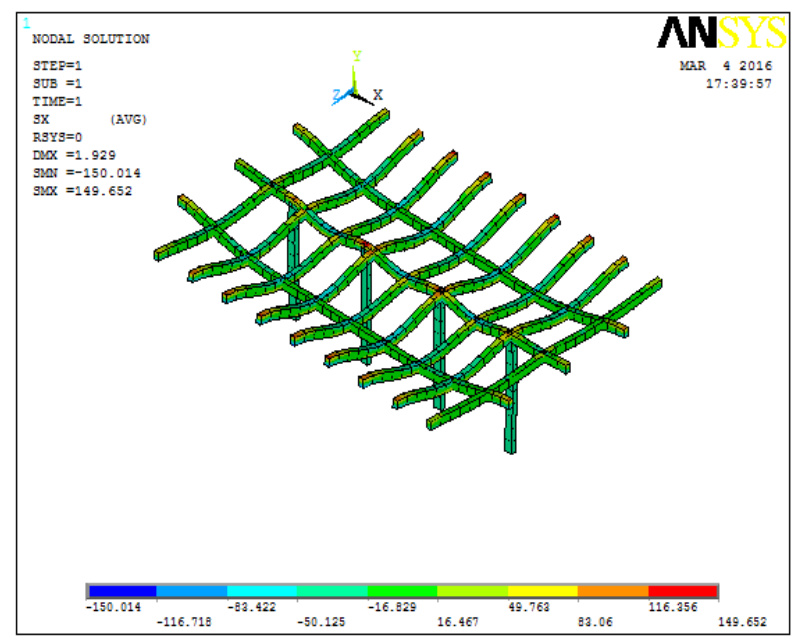

Figure 5. Stress of upper filter frame under work load 


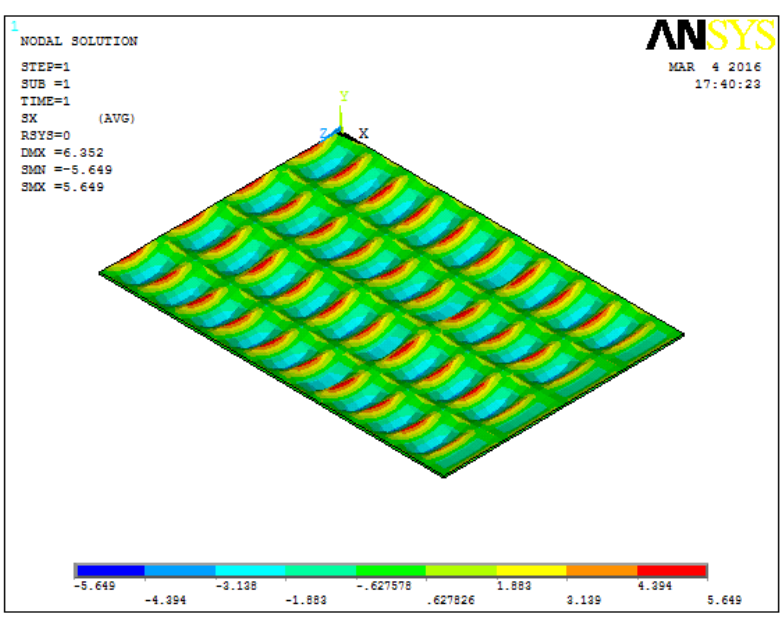

Figure 6. Stress of upper filter plate under work load

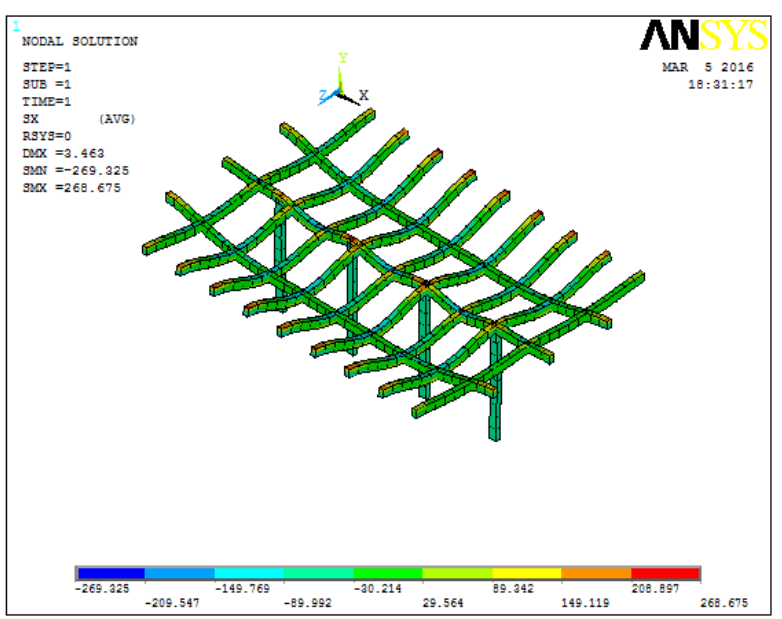

Figure 7. Stress of upper filter frame when back wash

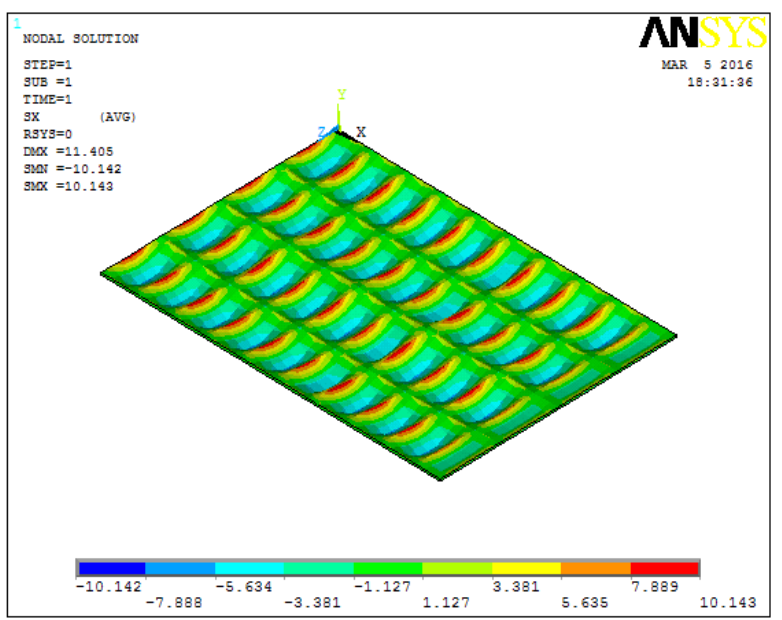

Figure 8. Stress of upper filter plate when back wash

From Fig. 5 6 we find that the largest deformation of the upper filter plate is about $6.4 \mathrm{~mm}$ and the largest stress of the filter plate is about $5.6 \mathrm{MPa}$. The largest deformation of the upper filter frame is about $1.9 \mathrm{~mm}$, and the largest stress of the frame is about $150.0 \mathrm{MPa}$. At the same time, the results show that the middle longitudinal beam is most dangerous because the largest stress occurs in the middle longitudinal beam.
From Fig. 7 8 we know that the largest deformation of the upper filter plate is about $11.4 \mathrm{~mm}$ and the largest stress of the filter plate is about $10.1 \mathrm{MPa}$. The largest deformation of the upper filter frame is about $3.5 \mathrm{~mm}$, and the largest stress of the frame is about 269.3 MPa. Just like the case in the normal work load, when back wash, the middle longitudinal beam is most dangerous too.

Under the back wash load, the stress of upper frames is larger than the yield limit of Q235B steel and not safe. That is to say, the upper filter frames must be reinforced. There are two reinforcing ways: changing the middle longitudinal beam with lager beam or increasing the number of the supporting tubes.

\section{Strength analysis of the first reinforced upper filter system}

The first reinforcing plan is changing the middle longitudinal beam from $120 * 80 * 5 \mathrm{~mm}$ to $120 * 120 * 5 \mathrm{~mm}$. Fig. 9 10 are the analytical results of the first reinforced upper filter system under work load and Fig. 11 12 are the analytical results of the first reinforced upper filter system under back wash load.

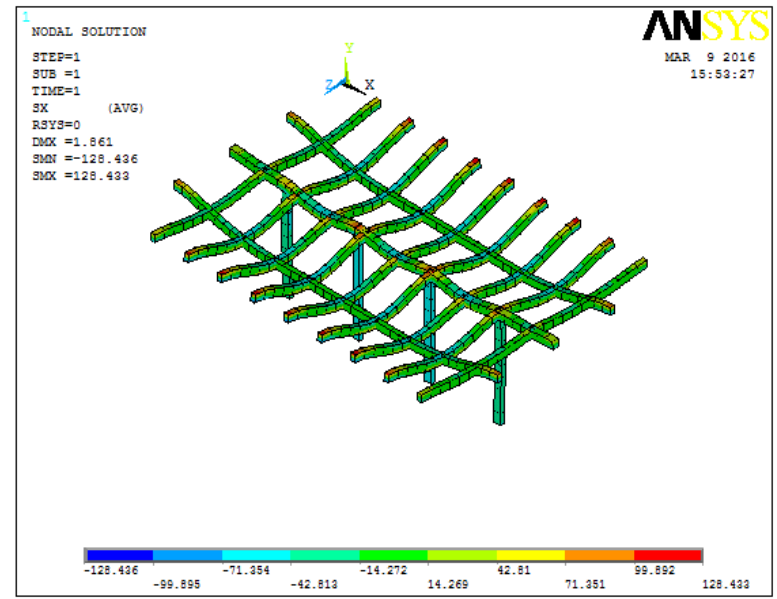

Figure 9. Stress of upper filter frame under work load

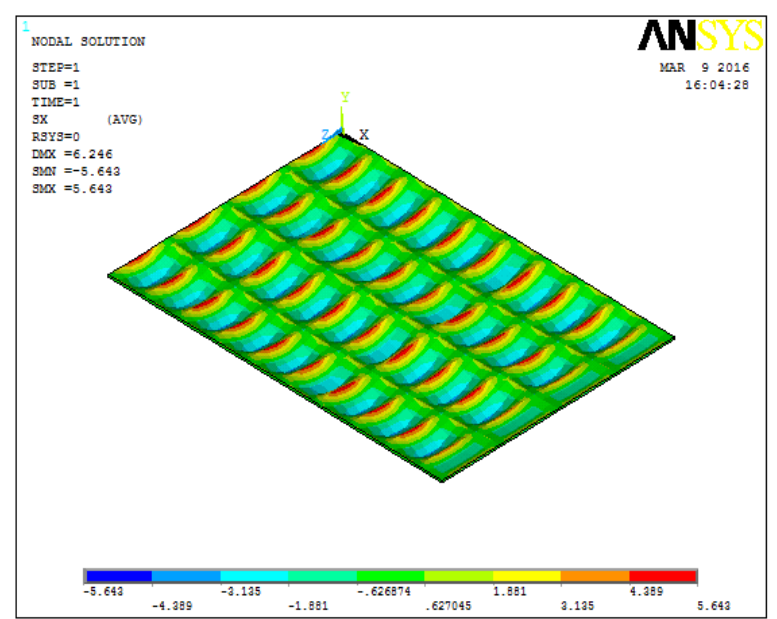

Figure 10. Stress of upper filter plate under work load 


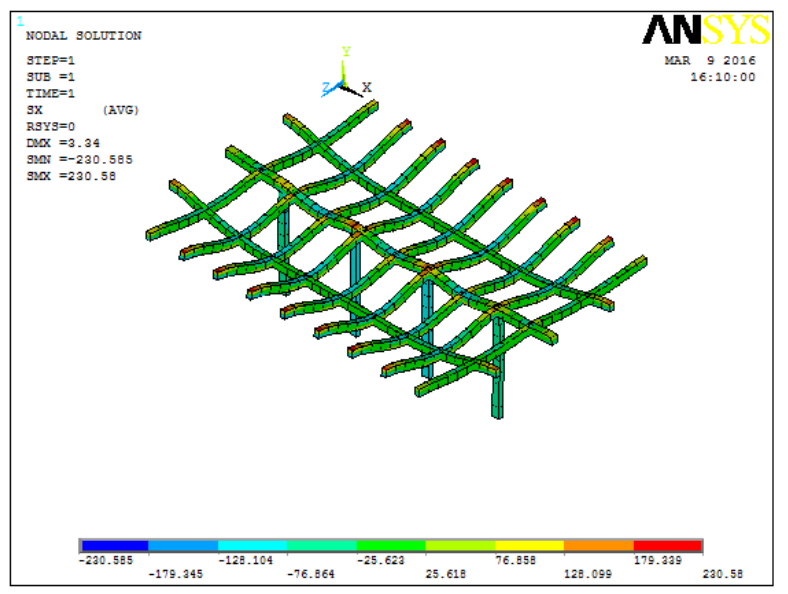

Figure 11. Stress of upper filter frame when back wash

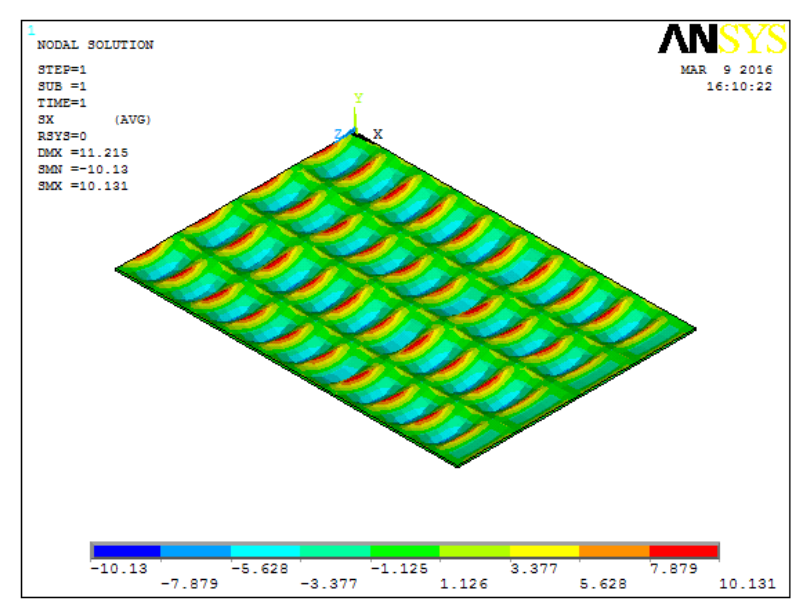

Figure 12. Stress of upper filter plate when back wash

\section{Strength analysis of the second reinforced upper filter system}

The second reinforcing plan is increasing another 4 supporting tubes under the flank longitudinal beams. As are shown in Fig. 13. Fig. 13 14 are the analytical results of the second reinforced upper filter system under work load and Fig. 15 16 are the analytical results of the second reinforced upper filter system under back wash load.

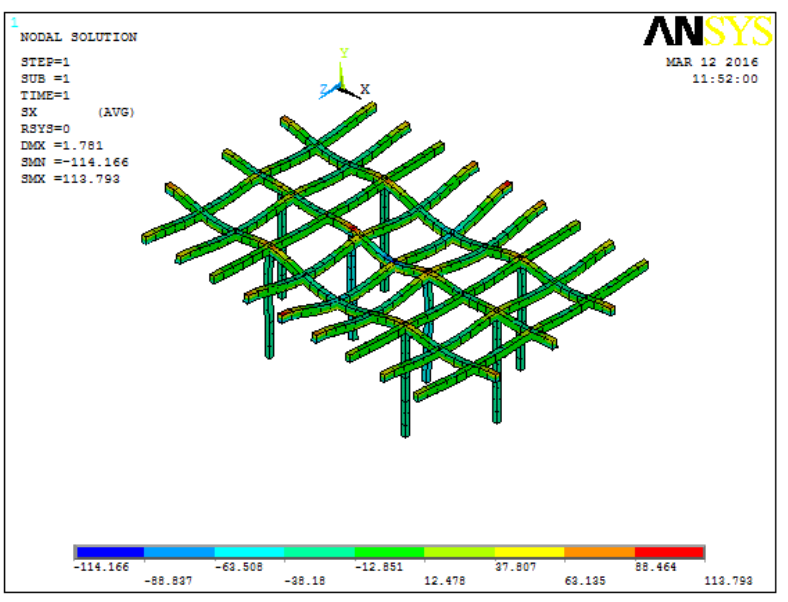

Figure 13. Stress of upper filter frame under work load

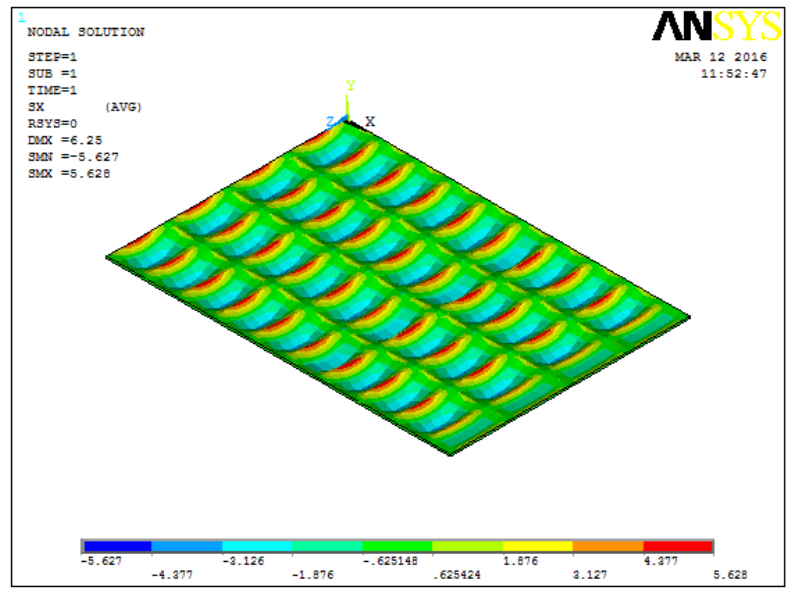

Figure 14. Stress of upper filter plate under work load

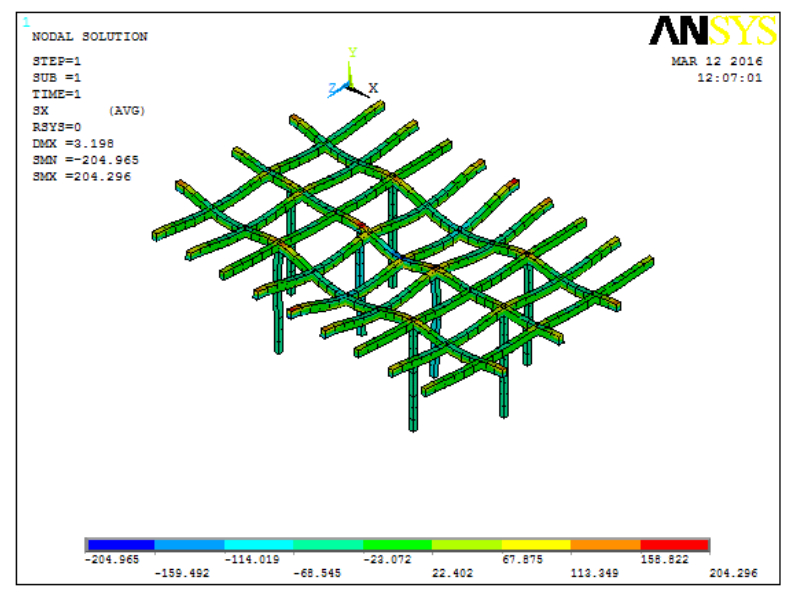

Figure 15. Stress of upper filter frame when back wash

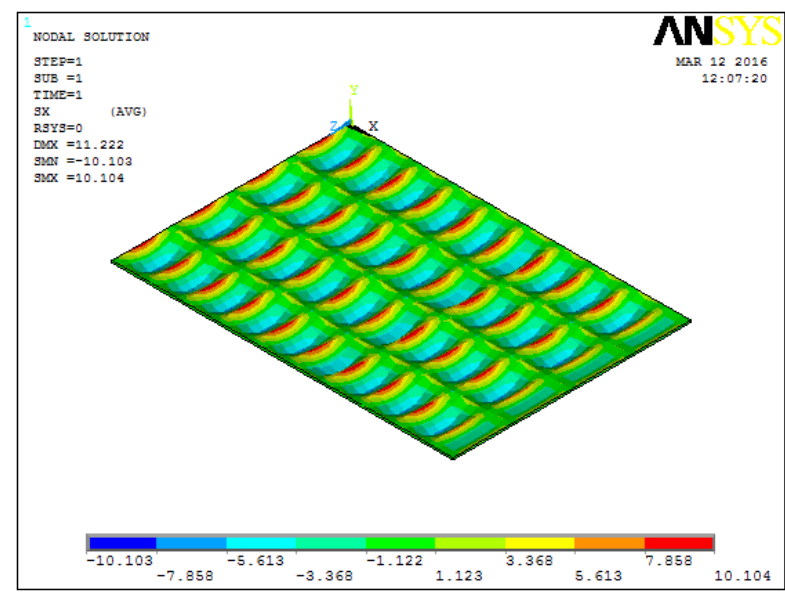

Figure 16. Stress of upper filter plate when back wash

\section{Summary}

From the analytical results we know that the upper filter system is in safety in normal work load. But when back wash, the original design has the largest stress $269.3 \mathrm{MPa}$, the first reinforced design is $230.6 \mathrm{MPa}$, and the second reinforced design has the smallest stress 205.0 $\mathrm{MPa}$. The second reinforced plan is the best design.

The deformations and stresses of the upper filter system under the normal work load and back wash load are shown in Table 1 and Table 2 respectively. 
Table 1. Deformations and stresses of the upper filter frames

\begin{tabular}{|c|c|c|c|c|}
\hline \multirow{2}{*}{ Plan No. } & \multicolumn{2}{|c|}{ Work load } & \multicolumn{2}{c|}{ Back wash load } \\
\cline { 2 - 5 } & Deformation & Stress & Deformation & Stress \\
\hline 1 & 1.9 & 150.0 & 3.5 & 269.3 \\
\hline 2 & 1.9 & 128.4 & 3.3 & 230.6 \\
\hline 3 & 1.8 & 114.2 & 3.2 & 205.0 \\
\hline
\end{tabular}

Table 2. Deformations and stresses of the upper filter plates

\begin{tabular}{|c|c|c|c|c|}
\hline \multirow{2}{*}{ Plan No. } & \multicolumn{2}{|c|}{ Work load } & \multicolumn{2}{c|}{ Back wash load } \\
\cline { 2 - 5 } & Deformation & Stress & Deformation & Stress \\
\hline 1 & 6.4 & 5.6 & 11.4 & 10.1 \\
\hline 2 & 6.2 & 5.6 & 11.2 & 10.1 \\
\hline 3 & 6.3 & 5.6 & 11.2 & 10.1 \\
\hline
\end{tabular}

\section{References}

1. Cheng Daxian. Mechanical Design Handbook. $5^{\text {th }}$ Edition. Beijing: Chemical Industry Press, 2008

2. $\mathrm{Xu}$ Zhilun, Elasticity Mechanics. $4^{\text {th }}$ Edition. Beijing: Higher Education Press, 2006

3. Chen Jingyi. Manual of Computer Aided Engineering Analysis of ANSYS. 1st Edition. Beijing: China Railway Press, 2001

4. T. R. Chandrupatla. Introduction to Finete Elements in Engineering. 1st Edition. Beijing: China Machine Press, 2008

5. ANSYS Inc. ANSYS Structural Analysis Guide Release 5.4 Third Edition. SAS, IP Inc., 1997

6. Zienkiewicz O C, Taylor R L. The Finite Element Method: The Basis. $5^{\text {th }}$ Edition. Volume 1, Butterworth-Heinemann, Oxford, 2000 